\title{
TIPSS is a promising alternative for portal vein thrombosis
}

\section{Susana G. Rodrigue \\ Sebastian Sixt \\ Juan G. Abraldes \\ Andrea De Gottardi \\ Christoph Klinger \\ Jaime Bosch \\ Iris Baumgartner \\ Annalisa Berzigotti}

\section{Video Byte}

Keywords: TIPSS, patency, cirrhosis, complication, endovascular therapy, portal vein, splanchnic thrombosis, portal hypertension, anticoagulant, systemic review, meta-analysis, Alimentary Pharmacology \& Therapeutics, Susana G. Rodrigues, Sebastian Sixt, Juan G. Abraldes, Andrea De Gottardi, Christoph Klinger, Jaime Bosch, Iris Baumgartner, Annalisa Berzigotti

Posted Date: September 20th, 2019

DOI: https://doi.org/10.21203/rs.2.15140/v1

License: (9) This work is licensed under a Creative Commons Attribution 4.0 International License. Read Full License 


\section{Abstract}

Untreated portal vein thrombosis (PVT) leads to the onset or worsening of portal hypertension Anticoagulation is the mainstay of PVT treatment but its efficacy is not ideal Transjugular intrahepatic portosystemic shunt (TIPSS) can be used for portal vein recanalization after thrombosis This systematic review and meta-analysis evaluated published data on the efficacy and safety of endovascular therapy in PVT The results from 399 patients showed that TIPSS placement was feasible in 95\% Major complications occurred in 10\%, and additional catheter-directed thrombolysis was associated with more complications The portal vein recanalization rate was $79 \%$ at 12 months The results were limited by a small sample size, largely heterogeneous data and the use of non-controlled, retrospective cohorts This study concluded that TIPSS for PVT recanalization was highly feasible, effective, and safe Randomized trials comparing TIPSS to anticoagulation are therefore needed These future studies will guide clinical decision-making for PVT treatment Rodrigues et al. "Systematic review with meta-analysis: portal vein recanalisation and transjugular intrahepatic portosystemic shunt for portal vein thrombosis." Alimentary Pharmacology \& Therapeutics 